Cos

\title{
limiar
}

VOL.1 - $N^{\circ} 1-2^{\circ}$ SEMESTRE 2013

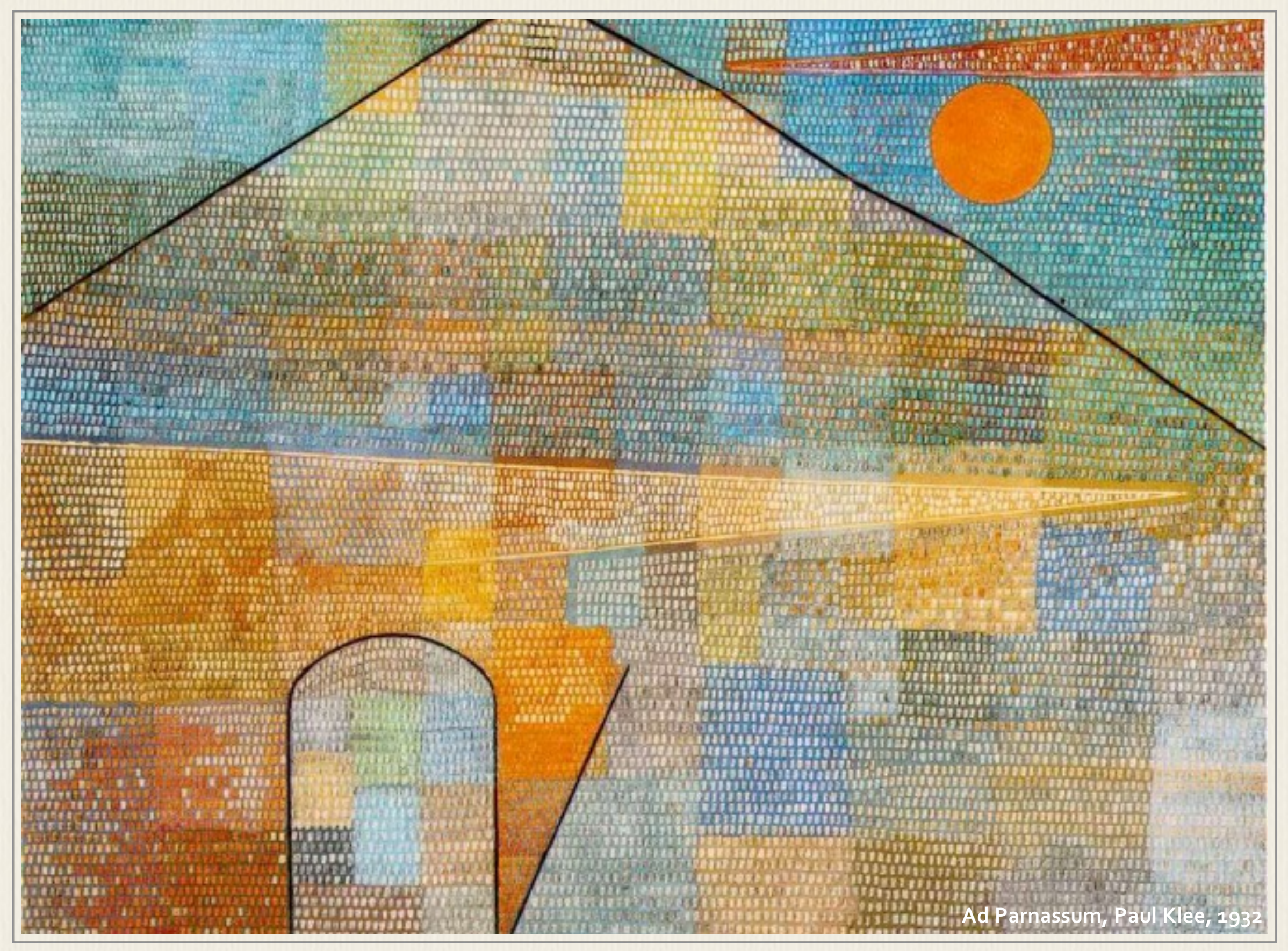




\section{Histórias de Mercadores de Arte}

Cristiane Rebello Nascimento

EFLCH|UNIFESP

Comento aqui um livro bastante interessante a respeito da formação do mercado de arte ao longo do século XX, que traz a vantagem adicional do estilo saboroso, que não se esquiva de relatar passagens pitorescas e picantes que envolvem figuras de destaque no cenário internacional e até o Vaticano. Trata-se de Mercadores de Arte (Planeta, 2004), livro de memórias de Daniel Wildenstein, que representa a terceira geração da mais bem sucedida, respeitada e poderosa família de marchands de arte do mundo. Embora a edição brasileira quase completa uma década, o livro permance atual, uma vez que tem como pano de fundo o mercado de arte, que continua a alimentar-se dos miraculosos furtos de obras de arte. $\mathrm{O}$ último caso noticiado terminou de maneira gauche, com as obras queimadas logo após o furto no forno da casa da mãe de um dos ladrões, na Romênia. Refiro-me às sete telas furtadas, em outubro de 2012, do Museu Kunthal, de Rotterdam, na Holanda - obras de Pablo Picasso, Henry Matisse, Paul Gaugin, Claude Monet, Meijer de Haan, e Lucien Freud - avaliadas entre 50 e 100 milhões de euros.

O livro toca também num tema que foi bastante noticiado nas últimas décadas, o do confisco de obras de obras de arte pelos nazista durante os progroms, e dos processos de devolução aos herdeiros que ocorreram no final do século XX. Desde 1998, a Declaração de Washington obriga os atuais donos de obras de obras de arte, incluindo os museus, a devolver aos herdeiros todos os objetos de arte confiscados pelos nazistas. No leilão do dia 08 de novembro de 2006, por exemplo, realizado pela Christie's, em Nova York, foi vendida, por 38 milhões de dólares, a tela "Berliner Strassenszner”, pintada em 1913, por Ernest Ludwig Kirchner. A obra, que fazia parte da coleção do Museu Brücke, desde 1980, foi devolvida a Anita Halpin, neta e herdeira do fabricante de sapatos Alfred Hess, na metade de 2006.

Também faria parte deste mesmo leilão da Christie's a tela de Pablo Picasso, “Ángel Fernández de Soto" (1903), avaliada entre 40 e 60 milhões de dólares. A obra, porém, foi retirada do leilão devido ao processo de devolução movido pelo herdeiro do proprietário original, o banqueiro Paul Von Mendelssohn-Bartholdy, que em 1935, vítima de uma campanha de intimidação dos nazistas, abandonou sua mansão e vendeu a sua significativa coleção de arte. Atualmente, a obra pertence a Andrew Lloyd 
Weber, autor dos musicais "Evita”, “Cats”, e o "Fantasma da Ópera”, que a adquiriu, em 1995, num leilão realizado pela Sotheby's. Ainda neste mesmo leilão da Christie's, foram vendidas quatro telas de Gustav Klimt, igualmente confiscadas pelos nazistas, e restituídas ao herdeiro dos proprietários originais, Ferdinand e Adele Bloch-Bauer, após quase dez anos de litígio. As obras devolvidas aos herdeiros correspondiam a 10 por cento das peças do leiloadas em Nova York.

A disputa em torno do quadro de Picasso, em particular, traz à tona uma questão muito atual no mercado das artes: a das dificuldades legais e comerciais em que se encontram os marchands, os museus e os colecionadores, diante de obras de arte que foram roubadas às famílias judias e aos museus pelos nazistas. Em geral, observa-se que as obras devolvidas voltaram para o mercado quase que imediatamente, como ocorreu com a tela de Kirchner: isso significa que, da noite para o dia, os herdeiros se tornaram milionários, e que os antigos proprietários, colecionadores ou museus, se vêem destituídos de obras que estavam em sua posse há décadas, ou pelas quais pagaram milhões de dólares. Entre uma coisa e outra, muitos intermediários lucram alto: os advogados, os marchands e as casas de leilões. Evidencia-se que a decisão judicial estava perfeitamente de acordo com o jogo do mercado de arte: devolver as obras aos herdeiros reaqueceu o mercado de arte, que continua a se tornar a cada dia um negócio mais lucrativo. Fica a dúvida se, depois de tantas décadas, não seria mais legítimo, que os herdeiros doassem as obras a museus, ao menos quando já fizessem parte de algum acervo, onde pudessem ser usufruídas por todos.

É notória a confusão que os confiscos nazistas provocaram no mundo das artes: a dispersão de coleções privadas e de acervos públicos, quando não, a destruição de valiosas obras de arte. Logo após a guerra, o desconhecimento do paradeiro e da verdadeira autoria das obras que compunha esse enorme espólio de guerra nazista, assim como o baixo preço delas, aqueceu o então recente mercado de arte de forma só vista agora, nesses últimos leilões da Christie's e da Sotheby's, o que deu poderes inigualáveis aos marchands e às casas de leilões. Muitas peças valiosas continuam dispersas, irremediavelmente perdidas, ou cuidadosamente escondidas em coleção privadas, na Europa, e nas Américas; outras foram parar nos acervos de museus estrangeiros, a maioria deles americanos. O próprio Brasil foi beneficiado com essa confusão. Como é sabido, o significativo acervo do Museu de Arte de São Paulo foi comprado durante os anos finais da década de 40 e as aquisições apostaram em obras que podiam ser atribuídas a artistas de peso. Este é o caso da tela que representa a Transfiguração , cuja atribuição a Rafael Sanzio por parte do Museu obteve a chancela irrefutável do historiador da arte italiano, Roberto Longhi.

Mercadores de Arte é fruto de uma série de entrevistas que Daniel Wildenstein, então com 82 anos, concedeu ao jornalista francês Yves Stavridès, entre maio de 1998 e maio de 1999. Na França, o livro foi publicado pela editora Plon, em 2000, um ano antes de sua morte. Aparentemente, a razão que fez Daniel relaxar o voto de discrição que os Wildenstein aprenderam a manter em relação aos próprios negócios e aos 
seus seletos clientes - discrição esta, que ele diz reger inclusive a relação familiar - foi um gesto final de defesa da honra da família em relação à dupla acusação de traição da causa francesa e judaica que pesou sobre ela desde a segunda guerra.

Os Wildenstein foram acusados de fazer aliança com os nazistas e vender obras de arte roubadas de famílias judias - informação que o autor sonega até o fim ao seu leitor, mas que aquele que a conhece de outras fontes percebe que está implícita na articulação geral do livro. Como se esperaria de comerciantes de alta-classe, eles próprios parte do seleto grupo de poderosos e ricos que constituem a sua clientela, a defesa de Daniel é uma lição de desenvoltura social e savoir-faire. A rigor, o livro inteiro funciona como uma apologia implícita da família Wildenstein, ainda que, como disse, o autor não mencione as acusações, e nem mesmo chegue a desqualificar os seus difamadores. A única exceção é André Malraux, a quem denuncia por ter se valido de sua posição de ministro da cultura para difamar e perseguir seu pai, Georges Wildenstein, acusando-o de tentar retirar ilegalmente do território francês a tela A Cartomante, de George de La Tour.

Um pouco à maneira de um espelho de príncipe, ou talvez de uma crônica nobiliária, os relatos de Daniel compõem positivamente um retrato exemplar da família Wildenstein. A saga da família começa com Nathan, avô e herói de Daniel, o qual, diante das perguntas do neto a respeito das origens da família, responderia: "Daniel, só existem duas coisas que contam de verdade. Amar a França. E ir ao Louvre”. Quando foi em busca de velhas certidões, a pedido de Yves Stavridès, Daniel teria descoberto algo surpreendente a respeito de sua família: seu avô, o homem que ele mais respeitou e ouviu em sua vida, mentira a respeito de sua origem asquenaze, da existência de mais três irmãos e três irmãs, e da existência de seu pai (ele dizia ser filho único de um rabino sefardim, morto antes de seu nascimento). Longe de ficar desapontado com a descoberta, Daniel faz da mentira do avô, contada logo no início do livro, o alicerce que estruturará os atributos que distinguem a linhagem dos Wildenstein: $\mathrm{o}$ amor à pátria, à ética e à arte.

De acordo com Daniel, Nathan deixa a Alsácia, em 1870, quando da invasão prussiana à região, porque não queria se tornar alemão. O custo de sua escolha foi ter sido renegado pelo pai. No relato do neto, o amor pela França se revela em todos os atos de Nathan. Como não consegue ir diretamente para Paris, Nathan escolhe viver na cidade de Vitry-le-François, por uma razão absolutamente patriótica, e não menos anedótica: o nome François. Quando chegou à França, Nathan fez o serviço militar, foi assistente de alfaiate e vendeu tecidos. Começou a negociar arte por acaso, a pedido de uma cliente de Vitry, e isto o levou a Paris. Segundo Daniel, chegando lá, o avô passou dez dias no Louvre, "educando o olhar" de maneira completamente diletante, e nunca mais parou de visitar o museu; esta foi a sua escola de arte.

No retrato que Daniel faz do avô, Nathan tem um papel crucial não apenas na incipiente história do mercado de arte, mas também na redescoberta da arte francesa do século XVIII, que se encontrava completamente esquecida nas paredes dos edifícios públicos e das casas de famílias aristocráticas. Antes dele, ninguém dava importância aos nomes de 
Jean-Honoré Fragonard, Jacques-Louis David e François Boucher, que compunham as três últimas gerações de pintores do ancien-régime. Esta foi a sua obsessão por toda a vida, junto com o amor pelos cavalos, outra marca familiar. O comércio de gado e de cavalos, conhecida "atividade de trapaceiros”, como diz Daniel, era a verdadeira ocupação do pai de Nathan na Alsácia. Esse fato, contudo, para ele, em nada desmerece a origem da família; também a família do banqueiro Albert Kahn ocupava-se desta atividade na Alsácia. Além disso, graças aos ensinamentos de Nathan a respeito de cavalos, o próprio Daniel tornou-se um dos mais importantes donos de escuderia de cavalos de corrida do mundo, o que é, evidentemente, um dado de nobilitação.

Além de se constituir, como disse, numa apologia implícita da honra dos Wildenstein, o livro é também um acerto de contas de Daniel com o pai. George sai ileso das acusações de Maulraux, mas não das do filho. O laço afetivo indissolúvel que Daniel constrói entre ele e o avô é a maneira que encontra de desqualificar o pai, que considera ter sido um mau pai, ausente e rigoroso demais. Ele, assim como o avô, é carismático, amante de cavalos, bom negociante, conhecedor da arte do século XVIII e apreciador dos impressionistas. Os interesses de Georges, ao contrário, resumiam-se à obsessão pela mãe, pela arte e pelos livros. Nas palavras de Daniel, era uma "biblioteca ambulante", tinha uma memória fenomenal para imagens e gostava de se cercar de intelectuais e de loucos. Além disso, a proximidade que manteve com os dadaístas teria causado horror em Nathan, amante do século XVIII. Era mais um colecionador que um marchand: não queria vender o que comprava, e comprava não só escultura e pintura, mas também livros raros e iluminuras.

Os relatos de Daniel deixam claro que a sua vida foi determinada por uma aguçada competição com o seu pai, da qual se sentia vitorioso, já que foi mais bem sucedido do que o pai como administrador dos negócios da família. Também no conhecimento da arte não ficou muito atrás, isso a despeito de George ter sido supostamente avaro com ele na partilha de sua enorme erudição. Daniel deixa mesmo entrever uma mágoa juvenil por não ter sido objeto de admiração do pai; para compensar esse suposto descaso, poucas das muitas grandes figuras que comparecem em seus relatos não o acharam totalmente encantador desde a mais tenra infância, e se interessaram de verdade pelo seu sucesso.

A prova mais eloqüente do carisma e da extraordinária qualificação de Daniel como marchand, que ele próprio se preocupa em oferecer ao leitor, envolve uma não menos extraordinária obra de arte, a Pietà, de Michelangelo, e um "amigo" muito inusitado, o papa Paulo VI. A crer nele, se hoje a célebre escultura de Michelangelo não se encontra em alguma coleção privada, afastada dos olhos da multidão de fiéis católicos e turistas que visitam diariamente a Basílica de São Pedro, isso se deve a Daniel Wildenstein.

Ele conta que, em meados da década de 70, foi chamado ao Vaticano pelo papa, que desejava vender a Pietà para levantar fundos para os pobres do Terceiro Mundo. Ao invés de aceitar a proposta, com a qual lucraria uma soma inimaginável, Daniel dissuade o papa desta empreitada, alertando-o 
para os danos que a venda da obra causaria à imagem da igreja, ainda mais se fosse mediada por um judeu.

As histórias de Daniel não vão muito além da década de 70 e 80; uma razão clara é que um marchand não deve, e, nem sempre pode, revelar os detalhes dos clientes e das obras que foram vendidas recentemente. Sigilo e discrição é a alma deste negócio.

Seus relatos descrevem um modus operandi de um período do mundo das artes que se extingue, emblematicamente, com a morte de Federico Zeri, um dos grandes experts ou connaisseurs da arte italiana, depois de Roberto Longhi e de Bernard Berenson. Neste período, que dura em torno de um século, há o surgimento concomitante do campo disciplinar da história e da crítica da arte, da figura do expert e do marchand. Até pelo menos a década de 50, o historiador da arte deveria associar as pesquisas documentais relativas às obras de arte, com as qualidades do expert, ou seja, possuir um imenso repertório visual que lhe permitisse atribuir obras de arte baseado no "olho" e na intuição. A figura, hoje obsoleta, deste tipo de expert, puramente intuitivo, totalmente confiado no olho senão no nariz, nasce dos esforços de repertorização e catalogação das obras de arte, iniciados no fim do século XIX, que informavam diretamente o mercado das artes.

Sempre que havia dúvidas em relação à atribuição de obras de arte que estavam no mercado, era ao expert que os marchands recorriam. Em muitos casos, a atribuição limitava-se ao reconhecimento da pertença da obra a uma determinada escola artística e da hipótese de uma datação aproximativa. Quando se tratava de apontar uma autoria de importância, o expert deveria ter o cuidado de expressá-la enquanto opinião, como fazia Federico Zeri. Afinal, a chancela da opinião do expert poderia arruinar ou tornar milionário um colecionador, ou um acervo de museu, da noite para o dia. Uma afirmação errônea de sua parte poderia inclusive levantar suspeitas quando à idoneidade de sua conduta. O caso é que também os experts lucravam alto. Tanto Bernard Berenson, quanto Federico Zeri, ambos consultores da Casa Wildenstein, ficaram muito ricos e tornaram-se eles próprios importantes colecionadores de arte.

Nos dias de hoje, os métodos de atribuição e de análise das obras de arte são outros: além das buscas por documentos nos arquivos empoeirados, o historiador da arte dispõe dos recursos tecnológicos, tais como raio-X, infra-vermelhos, exames químicos dos pigmentos, que permitem estabelecer uma datação ampla, mais segura das obras. Os novos especialistas de arte, aí incluído o historiador, agem cada vez mais como cientistas e divulgadores. Prova disso é, entre tantos exemplos, a série de documentários a respeito da vida e da obra de Leonardo da Vinci, produzidos pela televisão inglesa nos últimos anos, que o tratam como o modelo premonitório do cientista, e as suas obras, como provas materiais de seus métodos. Nem é preciso dizer que, se não fosse por tal anacronismo cientificista, Leonardo não faria tanto sucesso entre o grande público contemporâneo. Transformado já no maior inventor de geringonças de todos os tempos, como o helicóptero, o escafandro, a avião, o relógio de pulso, a bicicleta e a moto, o submarino, e o paraqueda, cujo propótipo foi recentemente fabricado e testado no Brasil, surpreende que ainda não tenha sido lançada a hipótese de que Leonardo, ao 
inventar os efeitos de sfumatura, estaria também adiantando a fotografia em 500 anos.

Esforço de divulgação científica semelhante ocorreu em relação a Michelangelo Buonarroti, o qual, numa rocambolesca trama imaginada por dois médicos brasileiros, foi transformado de pintor, escultor e arquiteto, em anatomista. Em todos os casos mencionados, o que se observa é que, a despeito, ou talvez, pour cause da democratização da arte através do número cada vez maior de mega-exposições, e de documentários televisivos, ela nunca esteve tão desprestigiada. Como diz Daniel Wildenstein, tratando-se de arte, “é melhor olhar o que está sobre o quadro". 